\title{
Significados da espiritualidade para pacientes com câncer em cuidados paliativos
}

\author{
Significance of spirituality for patients with \\ cancer receiving palliative care
}

\author{
Andréa Carolina BENITES ${ }^{1}$ \\ Carmen Maria Bueno NEME ${ }^{2}$ \\ Manoel Antônio dos SANTOS 3
}

\begin{abstract}
Resumo
Este estudo teve por objetivo compreender as vivências de pacientes com câncer em cuidados paliativos e o significado da espiritualidade ante a dor do adoecimento e a possibilidade de morte. Participaram 10 pacientes adultos e idosos com diagnóstico de câncer avançado, atendidos na enfermaria de cuidados paliativos/dor de um hospital oncológico. Foi utilizado o método fenomenológico para coleta e análise dos relatos, que foram obtidos a partir de entrevistas individuais. Desvelaram-se duas categorias temáticas: Fé como esperança de cura, apoio e confiança e a busca de sentido/ressignificação da vida; e A busca de sentido na morte e nas crenças sobre o pós-morte e a vivência da transcendência. Evidenciou-se a importância da dimensão espiritual na vivência do processo de morrer, possibilitando a busca de sentidos para a vida e para a morte. Este estudo revelou que estar ante a morte leva à veneração da vida, remetendo às crenças pessoais e ao que se busca como sentidos para o viver.
\end{abstract}

Palavras-chave: Cuidados paliativos; Espiritualidade; Fenomenologia; Neoplasias.

\begin{abstract}
This study aimed to understand the experiences of cancer patients receiving palliative care and the significance of spirituality when coping with the pain caused by the illness and facing the possibility of death. A total of 10 adults and older adult patients diagnosed with advanced cancer being treated in the palliative care/pain ward of a cancer hospital participated in this study. The phenomenological method was used to collecting and analyzing patients' reports, which were obtained by individual interviews. Two thematic categories emerged, namely: Faith as hope for healing,
\end{abstract}

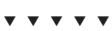

1 Universidade Estadual Paulista "Júlio de Mesquita Filho", Faculdade de Ciências, Programa de Pós-Graduação em Psicologia do Desenvolvimento e Aprendizagem. Av. Engenheiro Luiz Edmundo Carrijo Coube, 14-01, Vargem Limpa, 17033-360, Bauru, SP, Brasil. Correspondência para/Correspondence to: A.C. BENITES. E-mail: <benites.acb@gmail.com>.

2 Universidade Estadual "Júlio de Mesquita Filho", Faculdade de Ciências, Departamento de Psicologia. Bauru, SP, Brasil.

3 Universidade de São Paulo, Faculdade de Filosofia, Ciências e Letras de Ribeirão Preto, Departamento de Psicologia. Ribeirão Preto, SP, Brasil.

Artigo elaborado a partir da dissertação de A.C. BENITES, intitulada "Vivências de pacientes com câncer em cuidados paliativos e o significado da espiritualidade". Universidade Estadual Paulista "Júlio de Mesquita Filho", 2014.

Apoio: Fundação de Amparo à Pesquisa do Estado de São Paulo (Processo nº 2012/13092-8). 
support, and trust, and search for life meaning and resignification; and Search for meaning of death and beliefs in an afterlife and in a transcendence realm. The importance of the spiritual dimension was highlighted in the experience of the dying process, allowing the search for the meaning of life and death. The present study revealed that facing death leads people to greatly cherish life, connecting them to their personal beliefs and to their search for a purpose in life.

Keywords: Palliative care; Spirituality; Phenomenology; Neoplasms.

Estudos têm demonstrado a existência de relações entre religiosidade/espiritualidade, qualidade de vida e saúde, destacando a importância dos aspectos religiosos e espirituais no processo de cura ou reabilitação de doenças, incluindo as condições crônicas. Esses estudos deram margem para novas pesquisas, que vêm abrindo espaço para a reflexão e o tratamento da pessoa enferma levando-se em consideração sua dimensão espiritual (Liberato \& Macieira, 2008; Penha \& Silva, 2012). Ao mesmo tempo em que a temática da religiosidade/ espiritualidade se destaca como campo promissor na pesquisa e na prática profissional em saúde, também se revela um caminho controverso e desafiador (Moreira-Almeida, 2007).

Embora os termos religião, religiosidade e espiritualidade sejam frequentemente utilizados como sinônimos e estejam intrinsecamente relacionados, apresentam características e significados diferenciados. A religião/religiosidade envolve um conjunto de crenças, linguagem e práticas institucionalizadas que se alicerçam em uma tradição acumulada, com seus símbolos, rituais, cerimônias e explicações próprias acerca da vida e da morte. Já a espiritualidade é universal e não se restringe a uma religião propriamente dita, cultura ou determinado grupo de pessoas, mas envolve valores pessoais e íntimos, constituindo-se naquilo que dá sentido à vida e, como tal, promove o crescimento pessoal e a reflexão acerca das experiências vividas (Guimarães \& Azevum, 2007; Saad, Masiero, \& Battistella, 2001). Para Kovács (2007), a espiritualidade possibilita a contemplação e a reflexão das experiências existenciais, além de nortear a busca do sentido da vida.

Frente a uma doença grave e suas repercussões psicossociais, a espiritualidade demarca seu papel e importância. Segundo Valle (2005), ela possibilita que o ser humano transponha o estado biológico e emocional de acordo com a sua vivência, manifestando o sentido profundo daquilo que o indivíduo é, bem como o modo como vive em seu cotidiano. A vivência religiosa, ou religiosidade, é descrita pela referida autora como um gênero específico de experiência espiritual, caracterizando uma das formas de expressar essa dimensão. Já a espiritualidade seria um elemento inerente ao ser humano.

No adoecimento por câncer, a dimensão espiritual propicia aos pacientes o desenvolvimento da esperança, de um significado para a doença e de um propósito e sentido para a vida, o que favorece o amadurecimento pessoal, a integridade e o enfrentamento da situação vivenciada (Liberato \& Macieira, 2008). A espiritualidade pode influenciar o modo como o paciente enfrenta o processo de adoecer e suas repercussões, bem como a maneira como atribui significados ao adoecimento e às intercorrências vivenciadas na trajetória de tratamento.

O câncer é um nome genérico atribuído a um conjunto de mais de 100 doenças, as quais têm em comum a proliferação desordenada de células que invadem tecidos e órgãos. Atualmente, é considerado uma condição crônico-degenerativa grave. Horta, Neme, Capote e Gibran (2003) realizaram um estudo com o objetivo de averiguar o papel da fé no enfrentamento do câncer. Os relatos dos participantes permitiram identificar os conteúdos psicoafetivos relacionados à fé e os associados à doença. Os resultados mostraram que a primeira possibilitou aos pacientes reagir com esperança diante do diagnóstico, o que auxiliou na adesão ao tratamento e na busca da cura ou da melhora da qualidade de vida. A fé contribuiu também para manter a confiança dos pacientes na equipe de saúde, favorecendo a superação das demandas negativas da doença e do tratamento, de modo que pudessem voltar a encarar a vida mais positivamente. 
No caso de pacientes que vivenciam uma doença neoplásica avançada e se aproximam da fase final de vida, observa-se que a espiritualidade propicia a busca por um propósito ou significado em suas vidas, auxiliando-os a transcender o desespero e o sofrimento (Ferrel, Ottis-Green, \& Economou, 2013; Puchalski, 2012, 2013; Puchalski et al., 2009). Estudos com pacientes em cuidados paliativos têm destacado intervenções as quais promovem a sensação de dignidade e sentido de vida. Nesse cenário adverso, o conceito de sentido de vida (MIL, Meaning in Life) tem despertado o interesse de psicólogos, médicos e pesquisadores das áreas de psico-oncologia, tendo como base a Logoterapia de Frankl (Fegg et al., 2010). Essa preocupação é compartilhada pelos estudos que focalizam a relação entre espiritualidade e bem- estar de pacientes em cuidados paliativos (Puchalski, 2012).

Em uma perspectiva transcultural, Kudla et al. (2015) descrevem um estudo de validação da escala Schedule for Meaning in Life (SMILE) para pacientes indianos que se encontram em cuidados paliativos, comparados com pacientes alemães. Os resultados evidenciaram diferenças entre as duas populações em alguns itens; aqueles relativos à espiritualidade e ao compromisso social foram mais frequentemente listados entre os indianos, ao passo que os referentes às relações sociais foram menos citados. O estudo mostrou que, para os indianos, a espiritualidade claramente se constitui como uma dimensão relacionada à busca do sentido de vida.

Asgeirsdottir et al. (2013) conduziram um estudo qualitativo baseado na abordagem fenomenológica, com o objetivo de investigar a dimensão espiritual de pacientes em cuidados paliativos por meio da avaliação da influência das experiências de espiritualidade em suas vidas e em seu bem-estar. Emergiram aspectos religiosos e não-religiosos da espiritualidade (relações familiares, o significado de Deus e bem-estar), destacando-se práticas espirituais que foram propulsoras do fortalecimento de recursos internos, da motivação e da esperança. A fé evidenciou-se como elemento fundamental da espiritualidade para os participantes do referido estudo e os autores ressaltaram a impor- tância da exploração da dimensão espiritual na prática profissional em cuidados paliativos.

Dobratz (2012) investigou narrativas de 44 pessoas em fase final de vida e que abordaram a questão da espiritualidade. Foram identificados quatro temas espirituais: sistemas religiosos de crenças e valores; sentido de vida, propósito e contato com outros; sistemas não religiosos de crenças e valores; fenômeno metafísico e transcendental. Por meio da análise das narrativas, observou-se que, apesar do grande número de respostas envolvendo crenças religiosas e não religiosas e valores, os temas a respeito do sentido de vida, propósito e contato com outros também foram aspectos importantes da dimensão da espiritualidade.

Olsson, Ostlund, Strang, Grassman e Friedrichsen (2010) realizaram um estudo buscando investigar processos sociais e psicológicos utilizados por pacientes em cuidados paliativos domiciliares para manter a esperança, apesar do avanço da doença e do risco iminente de óbito. Nesse contexto, a esperança aparece como forma de manutenção da vida - no sentido de preservar o sentido da mesma, além de comunicar-se com as pessoas próximas a respeito da vida e da morte -, bem como de preparação para a morte, favorecendo a aquiescência dos pacientes em relação à responsabilidade pelo futuro, tanto o próprio quanto de seus entes queridos, e à possibilidade de usufruírem, de certo modo, da crença na sobrevivência após a morte.

A experiência do adoecer pode se configurar como um acontecimento repleto de sentido, bem como um ganho existencial, pois, quando o homem encontra um sentido para seguir adiante, apesar dos obstáculos inerentes à vida, pode transcender as dificuldades imediatas impostas pelas circunstâncias adversas. Até mesmo na morte o sentido da vida se satisfaz, mobilizado pela ameaça da morte iminente e, consequentemente, pela luta desencadeada em prol da afirmação da vida ao se buscar o sentido da morte e do morrer, o que contribui para enriquecer esse processo com um sentido pleno ante a existência humana (Frankl, 2003; Moreira \& Holanda, 2010). 
A despeito do reconhecimento das necessidades espirituais dos pacientes e da crescente importância atribuída à dimensão espiritual na experiência do adoecimento e na prática dos profissionais de saúde, que tem sido encontrada de forma recorrente na literatura (Neme et al., 2010; Puchalski, 2013), ainda são escassos os estudos brasileiros no contexto dos cuidados paliativos com pacientes oncológicos. Nessa vertente, este estudo teve por objetivo compreender os significados da espiritualidade para pacientes com câncer em cuidados paliativos, visando contribuir com conhecimentos que possam nortear a reflexão e o cuidado espiritual oferecido pela equipe multiprofissional no Brasil.

\section{Método}

Trata-se de uma pesquisa qualitativa de inspiração fenomenológica, na qual foram identificadas, descritas e analisadas as vivências de pacientes com câncer em cuidados paliativos e o significado da espiritualidade para esses indivíduos nesse contexto específico. O método fenomenológico possibilita a busca da compreensão de aspectos da dimensão humana, pois parte da própria experiência e da existência concreta do sujeito. O objetivo do método fenomenológico é propiciar a constatação e a descrição do mundo-da-vida pelo viés do próprio sujeito. A descrição do vivido possibilita a ressignificação das vivências por meio do retorno da percepção e das memórias do sujeito ao momento imediato (Andrade \& Holanda, 2010; Forghieri, 1993). O pesquisador fenomenólogo privilegia o "retorno às coisas mesmas", o regresso ao fenômeno, à dimensão pré-reflexiva, isto é, ao modo como o fenômeno aparece e é vivido antes de ser tematizado e categorizado.

\section{Participantes}

Participaram do estudo cinco homens e cinco mulheres, com diferentes diagnósticos de câncer avançado, na faixa etária de 44 a 71 anos de idade,

272 internados na enfermaria da Unidade de Cuidados
Paliativos e Dor do Hospital São Judas Tadeu/Hospital do Câncer de Barretos. Como critérios de inclusão, o paciente deveria estar em cuidados paliativos exclusivos, mantendo, no mínimo, a capacidade de permanecer alguns períodos em estado vigil, sentado ou deitado, apesar do autocuidado limitado. Os critérios de exclusão foram: paciente gravemente incapacitado, em progressão de morte iminente ou com comprometimentos cognitivos ou auditivos graves, como os encontrados em diferentes tipos de quadros demenciais e deficiências cognitivas e auditivas, evitando-se, assim, possíveis dificuldades de compreensão da questão norteadora utilizada na entrevista.

Todos os pacientes convidados aceitaram colaborar com a pesquisa. O número final de entrevistados foi definido conforme as convergências e divergências observadas nos elementos utilizados para a compreensão do fenômeno. A saturação foi obtida ao se evidenciar a repetição de algumas falas e descrições do fenômeno, porém, mantendo-se igual número de participantes masculinos e femininos (Bruns, 2012).

Nos 10 participantes incluídos, predominou o baixo nível de escolaridade (ensino fundamental incompleto), destacando-se apenas dois com ensino superior completo. Nenhum participante estava exercendo qualquer tipo de ocupação/trabalho no momento e as ocupações anteriormente exercidas correspondiam ao nível de escolaridade de cada indivíduo. Todos os participantes referiram ter alguma religião, sendo que seis se declararam católicos, três evangélicos e um se apresentou como sendo espírita kardecista. Destes, dois afirmaram ser não praticantes: o espírita kardecista e um católico.

No que concerne ao diagnóstico, evidenciaram-se diversos tipos de câncer, predominando o de colo de útero e o gástrico. Todos os participantes apresentavam a doença oncológica em estado avançado, tendo sido transferidos para cuidados paliativos exclusivos. O diagnóstico e o início do tratamento foram tardios, pois parte dos pacientes havia recebido a notícia há menos de um ano. Além disso, a doença já estava avançada quando diagnosticada. Todos foram informados 
pela equipe médica, em algum momento, a respeito do avanço da doença, sua incurabilidade e a necessidade de cuidados paliativos. Na data da realização da entrevista, a maior parte havia recebido essa informação em um período que variou de um a 23 dias.

\section{Procedimentos}

Como instrumento de coleta de dados foi utilizada a entrevista fenomenológica, pautada na questão norteadora: "Como foi sua trajetória desde o diagnóstico até o momento atual e como é para você vivenciar este momento de sua vida, em relação a sentimentos, medos e expectativas futuras?". Por meio dos relatos, foi possível captar e expandir a compreensão das vivências dos pacientes nessa condição, aprofundando também a exploração dos significados atribuídos à dimensão espiritual no momento vivido.

Ao serem convidados a participar do estudo, os pacientes foram informados quanto aos procedimentos éticos envolvidos, conforme os dados contidos no Termo de Consentimento Livre e Esclarecido. Já as entrevistas foram realizadas nos leitos e imediações do hospital, mantendo-se o conforto e a privacidade, e foram audiogravadas mediante consentimento dos participantes. O período de coleta de dados transcorreu de janeiro a maio de 2013 e o estudo foi aprovado pelo Comitê de Ética em Pesquisa do Hospital do Câncer de Barretos (Protocolo $n^{\circ}$ 07836212.5.0000.5437).

A análise foi realizada a partir de passos propostos por Forghieri (1993) e Martins e Bicudo (1994). Dessa forma, os relatos obtidos foram transcritos na íntegra e literalmente e os conteúdos submetidos à redução fenomenológica. As transcrições foram lidas e relidas sucessivas vezes pela pesquisadora antes de lançar mão de qualquer análise, a fim de se apreenderem as unidades de significado, posteriormente organizadas em categorias temáticas. Estas buscaram refletir as vivências de pacientes com câncer em cuidados paliativos e o significado da espiritualidade ante o adoecer e o morrer.

\section{Resultados e Discussão}

A análise fenomenológica permitiu desvelar dois eixos temáticos: "Fé como esperança de cura, apoio e confiança e a busca de sentido/ressignificação da vida" e "A busca de sentido na morte e nas crenças sobre o pós-morte e a vivência da transcendência". Para ilustrar as categorias temáticas, serão utilizadas falas identificadas por nomes fictícios, a fim de preservar a identidade e garantir o sigilo das informações compartilhadas pelos participantes. As categorias serão apresentadas e discutidas de forma simultânea.

\section{Fé como esperança de cura, apoio e confiança e a busca de sentido/ ressignificação da vida}

Vivenciar o agravamento do processo de adoecimento e a possibilidade de morte iminente levou a reflexões sobre o sentido da vida e da morte, bem como à busca de recursos e apoio para lidar com o sofrimento advindo dessa condição. Dentre os diversos aspectos que emergiram e se desvelaram nos depoimentos, é possível compreender que a dimensão espiritual dos participantes propiciou a busca de sentidos para o viver baseados na esperança de cura e no suporte recebido:

Hoje, ela [fé] me mantém viva... apesar de saber tudo o que eu soube [prognóstico reservado]... mas é ela que me mantém viva pra poder... ter certeza que eu vou me curar e voltar a minha vida normal... . Acreditar mais em Deus e ter fé e esperança de que as coisas vão melhorar. Você poder olhar para a experiência de outras pessoas e ver que outras pessoas conseguiram, então você também pode conseguir, né (Sofia).

A experiência de Sofia sugere que a esperança se expressa como um aspecto norteador para a busca de sentido, corroborando as reflexões de Olver (2012). O autor destaca que os pacientes, mesmo sabendo estarem no fim da vida, expressam esperança quanto ao futuro e continuam fazendo planos de acordo com suas expectativas presentes. 
A vivência do processo de adoecer também trouxe a ressignificação da vida e dos valores pessoais: "Ah, mudou. A gente passa a dar mais valor na vida... passa a ter mais fé em Deus, a buscar mais fortaleza Nele, porque se não for Ele... nós não faz nada" (Flora). Nota-se a busca de sentido na luta e na convicção de que se deve viver um dia de cada vez:

Eu tô evoluindo mais, porque... quer dizer, que hoje, eu venci o dia de hoje, graças a Deus... mas tô esperando o de amanhã. $E$ se Deus quiser, vai ser a mesma coisa. Eu vou lutar e vou vencer (Antônio).

Tem muita gente que não... confia na fé. Mas eu confio, eu quero lutar pra mim viver. E eu vou me esforçar o máximo possível para que eu possa viver mais. E eu estou vendo que eu estou melhorando a cada dia mais, com calma, devagar, sem violência e sem estresse, sem nada (Marcos).

Os significados e a busca de apoio na dimensão espiritual se evidenciaram de forma peculiar para cada um, de acordo com a idade e o tempo decorrido entre o diagnóstico e o período em que estavam sob cuidados paliativos. Maria estava vivenciando o processo de adoecimento havia 33 dias e tinha iniciado os cuidados paliativos há apenas 17. O diagnóstico recente e a gravidade de seu quadro clínico mobilizaram a busca por apoio na afirmação da esperança de se curar, distanciando-se, assim, do "estar doente" e da possibilidade de se deparar com sua finitude. Ainda sem poder absorver completamente o choque desencadeado pelo diagnóstico devido à brevidade do processo, Maria travava a luta de cada dia, buscando valorizar o sentido de viver o presente para, então, redimensionar o futuro:

Às vezes eu penso assim: "por que eu?". Tem tantas pessoas que faz coisas más e eu não, nunca fiz. Mas eu não posso me julgar assim porque Deus é que sabe. Não que: "ah, eu vou aceitar a doença, eu vou esmorecer". Não é isso, eu vou lutar, e com Deus eu vou vencer. Não acabou, não. Enquanto tiver recurso, nós vamos lutar... (Maria).
Já para Gabriel, que estava convivendo com a doença havia mais de sete anos e passou a receber os cuidados paliativos há quatro meses, os significados do adoecer e da espiritualidade apareceram atrelados à franca constatação do limite e aceitação de sua finitude, bem como à revalorização da vida e da importância da luta diária por sua preservação. Mesmo assumindo uma postura resignada frente ao desfecho selado, o participante não se distanciou de sua realidade. Apesar das dores e incertezas, pôde se abrir às novas possibilidades existenciais que emergiram em sua longa trajetória de convívio com o diagnóstico, como o aprendizado de novos modos de ser e significar a vida:

A doença é grave. A gente sabe disso, tem consciência e... . A gente luta, mesmo sabendo que não é bom o resultado, mas... esperança a gente sempre tem. A gente tenta não desesperar, mas lá no fundinho tem. E é isso aí, a gente vem lutando, pelejando... . Ah, sei lá, as pequenas coisas... . Coisas de valor que ontem você pegava e hoje não tem mais valor. Assim, não é uma coisa importante, como sei lá... como uma flor... . É, talvez uma flor seja mais importante... . Muda sim, a gente não é a mesma pessoa. A vida não é só isso aqui que a gente vê um palmo na frente do nariz, a dois metros... é bem diferente (Gabriel).

Diferentemente de como parece ter ocorrido com Gabriel e Maria, as vivências de Marcos em seu processo de ressignificação da vida ocorreram no transcorrer do adoecer. Durante quase todo o período em que estava sob cuidados paliativos, Marcos vivenciou o processo com desesperança e acentuado humor deprimido. Porém, quando os sintomas físicos começaram a se estabilizar, iniciou um novo processo de ressignificação do adoecimento e da vida de maneira que a dimensão espiritual se expressou na esperança de obter o prolongamento da vida e da convivência com os familiares. Essa esperança se evidenciou de forma equilibrada e conforme a realidade vivida pelo participante:

Ah, eu vejo minha mãe, eu vejo os colegas... É umas que acha que a vida não vale nada, que ele vai morrer... mas eu não penso assim. 
A vida vale muito pra mim... . Não, porque antes eu pensava na morte: "ah, eu vou morrer mesmo, eu posso ficar sossegado". Mas agora eu ligo. Eu quero viver. Agora, se Deus não quiser, paciência. Mas, mesmo se ele não quiser, eu vou em frente. Eu vou até onde der (Marcos).

Para alguns participantes, a vivência do processo de terminalidade possibilitou a reflexão acerca dos aspectos que conferiam sentido para a vida, principalmente os direcionados para a valorização dos vínculos familiares e afetivos e a esperança na continuidade da convivência com pessoas significativas:

O que dá sentido pra minha vida? ... lutar... que é estar junto dos meus filhos, com a família ... em sair daqui, levantar dessa cama... curtir mais os meus filhos, curtir mais a minha familia. Dedicar mais o meu tempo a outras pessoas (Júlia).

Eu não perco a esperança, até onde tiver vida eu vou lutar. Pra acabar de criar eles. Essa dai é a mais velha [acompanhante do dia], depois tenho uma de 24, outra de 15 e uma de 12. A luta maior é por eles, né. Eu tenho fé em Jesus que eu vou vencer. Posso não vencer assim, né, mas eu queria pelo menos uns dois anos de vida [risos] (Flora).

Os resultados corroboram os achados de estudos que apontam a relação entre a espiritualidade, a manutenção da esperança e a atribuição de significados para a doença e para a vida. A espiritualidade propicia o senso de controle e ameniza o sofrimento vivido (Guerrero, Zago, Sawada, \& Pinto, 2011; Liberato \& Macieira, 2008). O modo como os participantes atribuíram sentido às suas vivências de sofrimento se aproxima do que Frankl $(1993,2003)$ postula em relação ao homem ter condições de encontrar sentido em qualquer situação humana por meio da tríade trágica, constituída pela dor, culpa e morte, bem como pelo amor e pela terminalidade. Desse modo, a experiência radical do ser "ante a morte" revela-se como um caminho por meio do qual se pode encontrar a vida e seu sentido.

\section{A busca de sentido na morte e nas crenças sobre o pós-morte e a vivência da transcendência}

Ao relatarem suas vivências do processo de adoecer e morrer, os participantes desvelaram suas concepções de morte, deflagrando uma reflexão acerca de sua própria finitude e de suas crenças a respeito do pós-morte. Os relatos revelaram compreensões da morte como um acontecimento inevitável da vida, como parte natural da existência e finalização do projeto existencial. Frente à angústia de encarar a morte como um fim em si mesmo, alguns participantes concentraram-se em reflexões pautadas em crenças religiosas acerca do pós-morte, focando a possibilidade da continuidade do existir. A procura de explicações sobre o pós-morte se destaca como uma busca de uma forma de lidar com a angústia da iminência da morte e das incertezas que esse fenômeno mobiliza no ser:

Ah, pra mim não preocupa nada, porque pra mim a morte é uma coisa normal. Se caso eu morrer, seja o que Deus quiser. Mas eu não tenho medo da morte... ah, a morte eu enxergo ela como uma coisa normal, onde todo mundo passa, ninguém escapa. Ainda mais agora. Mais um dia eu vou, eu não sei quando. Mas eu quero morrer com dignidade, sem nenhum problema (Marcos).

Ninguém quer morrer, todo mundo quer viver. Eu acho que morrer é muito fácil. Eu não sei se teria outro lado, se tem outro lado. Para mim, morrer é dormiu, apagou, puf. Eu acho que vai ser muito fácil, sem sofrer muito antes. Mas a gente não tem uma... uma conclusão de como vai ser isso.... é, o após é... indefinido, né. Aí, por isso que a gente falar é meio complicado. E cada religião fala uma coisa, é... espiritual mesmo comenta que tem outras vidas, né (Gabriel).

Francisco aborda a inevitabilidade da morte e sua possibilidade na existência concreta. A morte é percebida por esse participante como algo que não se pode evitar e também como um paradoxo, porque se vive tentando escapar dela, prorrogando sua chegada: 
A morte, não preocupo com a morte. Assim, eu encaro ela... . É, você fala assim: "oh, se você sair daqui, você vai morrer". Tudo bem, então aí eu quero morrer e aí vou embora. Então, eu encaro a morte... . É este desafio mesmo, que nós vamos tentar... vai morrer tentando. Todo mundo vai morrer tentando (Francisco).

Vivenciar a terminalidade propiciou a busca de sentidos no processo de morrer por meio de crenças relacionadas ao pós-morte e pela vivência da transcendência: "... eu tenho certeza que existe uma força maior na gente, né, porque se não a gente não existia" (Marcos). A vivência da transcendência compreende uma dimensão que vai além da experiência religiosa em si ou da convicção na existência de um ente superior, maior do que se é e mais além do que lhe é dado conhecer: " $A$ vontade de viver... essa crença em algo maior, que você não toca, não pode... Mas que você acredita que existe... Cada um acredita de um jeito, né?" (Sofia).

De acordo com Saporetti (2009), todos buscam transcender a existência concreta. Transcender envolve poder "ir além" do seu corpo, dos limites da alma e da possibilidade de conhecimento de Deus ou das demais representações da divindade ou mesmo ir além de si próprio. Diante da vivência da finitude, o ser se defronta consigo mesmo, retomando sua essência, ou seja, direcionando-se ao transcendente, conforme é possível compreender nos relatos das vivências dos colaboradores deste estudo: "Alguma coisa deve ter porque a gente não está aqui com um simples propósito de viver e morrer. Deve ter outro lado. Porque a gente sempre evolui, né. ... Por que a morte pararia, não é? Estou pensando assim" (Gabriel).

Para alguns participantes, a crença na continuidade da vida pós-morte contribui para atenuar a angústia da constatação da iminência da morte, levando-os a assumir a própria finitude:

Eu tenho esperança que, mesmo eu morrendo, eu continue a viver, após a morte... eu sei que a vida é eterna, mas e seu viver uns oito, 10 anos, pra mim tá bom. Agora, o restante Deus é que sabe, né... . Como eu posso viver, até quando posso viver.
Mas eu estou ainda na luta. Vamos ver o que Deus reserva pra gente (Marcos).

Eu acredito que tenha alguma evolução, sim. Mesmo depois da morte, talvez uma evolução que não seja compreendida nesse plano. Talvez começando outro plano, que vai ter uma... uma compreensão (Gabriel).

A ideia de continuidade da vida e/ou de um novo projeto existencial nega a possibilidade de um fim em si mesmo e atua na manutenção da esperança, fortalecendo a luta pela vida e a experiência da transcendência. A crença na sobrevivência dos contornos identitários mesmo após a morte parece desempenhar um papel importante na preparação para o desfecho iminente. Isso se evidenciou também nos estudos de Olsson et al. (2010). Os autores ressaltam que a crença na continuidade da vida auxilia na manutenção da esperança e na construção de perspectivas de futuro, bem como na redução do medo da morte.

Para Leonardo, o que dá sentido para seu existir agora é a iminência de sua própria morte e sua preparação para ela. Seu desejo de se desligar da vida coroa a vontade de encontrar repouso e alívio para as terríveis dores físicas que sente, livrando-se, assim, do fardo de intenso sofrimento e exaustão emocional que subjuga sua vontade de viver:

Meu descanso [a morte]. É o descanso de eu parar de sofrer com dor, com essas coisas todas... vou pedindo morfina, o quê que vai virar, né? Não vai virar nada, não está fazendo efeito nenhum. Ela está... Eu tomo morfina e melhora um pouquinho a dor... Dói bastante... Mas não é por aí que nós vamos desistir... Mas se Deus quiser... Eu espero que Deus me dê um bom descanso... . Eu queria descansar em paz... . Minhas coisas estão tudo certa, no cemitério o cadastro está feito. Todas as partes de funeral está feito, tudo essas coisas estão feitas, então eu acho que já podia dar um desconto... . Ah, eu não sei se eu... eu estou batalhando... (Leonardo).

Para este participante, o fato de ter acertado suas contas e resolvido suas pendências parece 
funcionar como uma fonte de alento. Naquele momento de sua vida, ao refletir sobre sua experiência, ele considera que já cumpriu sua tarefa existencial, o que abre espaço para que possa ratificar uma escolha.

Eu olho assim pra minha vida... Eu... Eu preciso... Eu queria ver meu filho crescer, mas... Hoje não é isso o que eu quero, eu quero descansar... Eu acho que eu já produzi o que tinha que produzir na Terra. Assim, minha parte já foi feita (Leonardo).

O desejo de morrer se revelou de forma cristalina em Leonardo como um fenômeno particular e divergente dos demais participantes deste estudo. Porém, essa manifestação não parece indicar um desejo suicida, mas uma aceitação das restrições e dos limites concretos da existência. Caracteriza um desligamento progressivo de sua relação com a vida, ao mesmo tempo em que transforma seus vínculos afetivos e prepara aqueles que ficariam após sua morte. Nesse caso, aspirar a morte se relaciona à busca da cessação do sofrimento físico, o que corrobora o estudo de Ohnsorge, Gudat e Rehmann-Sutter (2014), o qual destaca o desejo de morrer como uma forma de libertação do sofrimento. Essa realidade suscita reflexões acerca do contingente de pessoas que se encontram em estado avançado de uma doença progressiva e fatal e que não têm acesso a hospitais de referência para poderem se beneficiar desse tipo especial de cuidado que necessitam. Muitas vezes, esses pacientes passam pelo processo de morrer sem o controle apropriado de seus sintomas incapacitantes, sem adequada analgesia ou na mais absoluta solidão e abandono.

Durante o encontro, Leonardo expressou seu desejo de receber a visita de um padre. Seu desejo de morte mobilizou nele intensa angústia e sentimento de culpa. Algumas questões espirituais desencadeiam nos pacientes o medo de não receber o perdão de Deus, o receio advindo do desconhecimento acerca do que encontrarão no pós-morte e a falta de sentido na vida (Kovács, 2007). Dentre a multidimensionalidade da dor, como apresentada por Esslinger (2004), desvelou-se, para Leonardo, a dor espiritual, abrangendo as culpas que sentia pe- rante Deus e a busca de repará-las por meio da fé e da espiritualidade, evidenciada pela necessidade da visita do padre.

A análise das categorias identificadas nos depoimentos dos participantes levou à compreensão de experiências de espiritualidade similares às encontradas em outros estudos com pessoas em cuidados paliativos, como se constata na pesquisa fenomenológica de Asgeirsdottir et al. (2013), que ressaltam a importância de prover a dimensão espiritual na atuação em cuidados paliativos. Dobratz (2012) também investigou a espiritualidade de pessoas em fase final de vida e identificou a presença significativa de temas espirituais e de questões acerca do sentido da vida e sua importância nos cuidados prestados a esses pacientes.

Quando a doença evolui para a impossibilidade de cura ou reversão, o ser humano defronta-se concretamente com a inevitabilidade da morte e com o fim de seu projeto existencial. A perspectiva do rompimento e da separação dos vínculos afetivos propicia vivências únicas e possivelmente diferenciadas de tudo o que já possa ter vivido até então. Fé, espiritualidade e engajamento religioso, encontrados nos relatos de alguns dos participantes, também auxiliam no processo de aceitação da morte nos momentos em que ela se evidencia como certa e inexorável. Vivências de transcendência, propiciadas pelo exercício da espiritualidade e da fé, promovem a busca de sentido e de ressignificação de diversos aspectos da vida humana, redimensionando valores e o próprio processo de morrer.

Ao lado das vivências comuns evidenciadas nos relatos de todos os participantes, foi possível compreender que cada pessoa vive um momento particular e único, expressando um modo peculiar de ser de acordo com sua história de vida e concepções dominantes. As vivências de pacientes em cuidados paliativos, bem como as de seus familiares, devem ser identificadas, conhecidas e reconhecidas por todos os profissionais que assumem a tarefa de acompanhá-los nessa difícil etapa da vida de modo que sua presença seja realmente significativa, auxiliando no alivio da dor e do sofrimento. 


\section{Considerações Finais}

Os resultados deste estudo não se destinam a generalizações, tendo em vista que se focalizou a compreensão fenomenológica das vivências do paciente com câncer, especificamente no contexto dos cuidados paliativos. Foi possível compreender a importância da dimensão espiritual para que pessoas em condições de extrema vulnerabilidade consigam sobreviver à dor e ao sofrimento cotidiano, ressignificando, a cada momento, as experiências que vivem.

Salienta-se que, a despeito da consciência da possibilidade iminente da morte e de sua condição de paciente em cuidados paliativos, evidenciou-se o papel da dimensão espiritual na manutenção da esperança. Esta, em alguns momentos, deu lugar à expectativa de uma morte digna e sem sofrimento, entendida como desígnio divino que se impõe ao final de um longo processo de intensa luta pela cura ou pelo prolongamento da vida.

Frente à relevância da dimensão espiritual reconhecida na presente pesquisa, por conferir consolo, apoio e força psicológica a pessoas que se encontram na iminência da morte, sugere-se que estudos similares sejam empreendidos em pacientes com diversas patologias e em fases distintas do adoecimento, buscando também compreender os significados da espiritualidade para familiares, cuidadores e profissionais envolvidos no cuidado. O conhecimento das especificidades da dimensão espiritual na interface com a unidade de cuidado (paciente, família e equipe) pode aprimorar as práticas de humanização e atenção integral oferecidas ao paciente acometido por uma doença que ameaça seriamente a continuidade da vida. Alerta-se também para a necessidade de se prover formação e capacitação do profissional de saúde que transcendam os limites técnicos estabelecidos pelos protocolos da especialidade oncológica.

\section{Colaboradores}

A.C. BENITES e C.M.B. NEME colaboraram na concepção, na coleta e análise dos dados e na redação do artigo. M.A. SANTOS colaborou na análise dos dados,

\section{Referências}

Andrade, C. C., \& Holanda, A. F. (2010). Apontamentos sobre pesquisa qualitativa e pesquisa empíricofenomenológica. Estudos de Psicologia (Campinas), 27(2), 259-268. https://doi.org/10.1590/S0103166X2010000200013

Asgeirsdottir, G. H., Sigurbjornsson, E., Traustadottir, R., Sigurdardorttir, V., Gunnarsdottir, S., \& Kelly, E. (2013). "To cherish each day as it comes": A qualitative study of spirituality among persons receiving palliative care. Supportive Care in Cancer, 21(5), 1445-1451. https:// doi.org/10.1007/s00520-012-1690-6

Bruns, M. A. T. (2012). A redução fenomenológica em Husserl e a possibilidade de superar impasses da dicotomia subjetividade-objetividade. In M. A. T. Bruns \& A. F. Holanda (Orgs.), Psicologia e fenomenologia: reflexões e perspectivas (pp.65-76). $2^{\text {a }}$ ed. Campinas: Alínea.

Dobratz, M. (2012). All my saints are within me: Expressions of end-of-life spirituality. Palliative and Supportive Care, 11(3), 191-198. https://doi.org/ 10.1017/S1478951512000235

Esslinger, I. (2004). De quem é a vida, afinal? São Paulo: Casa do Psicólogo.

Fegg, M. J., Brandstatter, M., Kramer, M., Kogler, M., Haarmann-Doetkotte, S., \& Borasio, G. D. (2010). Meaning in life in palliative care patients. Journal of Pain and Symptom Management, 40(4), 502-509. https://doi.org/10.1016/j.jpainsymman.2010. 02.010

Ferrel, B., Ottis-Green, S., \& Economou, D. (2013). Spirituality in cancer care at the end of life. The Cancer Journal, 5(5), 431-437. https://doi.org/10.1097/PPO. 0b013e3182a5baa5

Forghieri, Y. C. (1993). Psicologia fenomenológica: fundamentos, método e pesquisas. São Paulo: Pioneira.

Frankl, V. E. (1993). A presença ignorada de Deus. Petrópolis: Vozes.

Frankl, V. E. (2003). Psicoterapia e sentido da vida. São Paulo: Quadrante.

Guerrero, G. P., Zago, M. M. F., Sawada, N. O., \& Pinto, M. H. (2011). Relação entre espiritualidade e câncer: perspectiva do paciente. Revista Brasileira de Enfermagem, 64(1), 53-59. https://doi.org/10.1590/S0 034-71672011000100008

Guimarães, H. P., \& Avezum, A. (2007). O impacto da espiritualidade na saúde física: revisão de literatura. Revista de Psiquiatria Clínica, 34(1), 88-94. Recuperado em março 3, 2014, de http://www.hcnet.usp.br/ipq/ revista/vol34/s1/88.html

Horta, C. R., Neme, C. M. B., Capote, P. S. O., \& Gibran, V. M. (2003). O papel da fé no enfrentamento do câncer. In C. M. B. Neme \& O. M. P. R. Rodrigues (Orgs.), 
Psicologia da saúde: perspectivas interdisciplinares (pp.149-172). São Carlos: Rima.

Kovács, M. J. (2007). Espiritualidade e psicologia: cuidados compartilhados. O Mundo da Saúde, 31(2), 246-255. Recuperado em março 3, 2014, de http:// pesquisa.bvs.br/brasil/resource/pt/ses-9572

Kudla, D., Kujur, J., Tigga, S., Tirkey, P., Rai, P., \& Fegg, M. J. (2015). Meaning in life experience at the end of life: Validation of the Hindi version of the schedule for meaning in life evaluation and a cross-cultural comparison between Indian and German palliative care patients. Journal of Pain and Symptom Management, 49(1), 79-88. https://doi.org/10.1016/j.jpainsymman. 2014.05.013

Liberato, R. P., \& Macieira, R. C. (2008). Espiritualidade no enfrentamento do câncer. In V. A. Carvalho, M. H. P. Franco, M. J. Kovács, R. Liberato, R. C. Macieira, M. T. Veit, ... L. Holtz (Orgs.), Temas em psico-oncologia (pp.414-431). São Paulo: Summus.

Martins, J., \& Bicudo, M. A. V. (1994). A pesquisa qualitativa em psicologia: fundamentos e recursos básicos. São Paulo: Educ.

Moreira, N., \& Holanda, A. (2010). Logoterapia e o sentido do sofrimento: convergências nas dimensões espirituais e religiosa. Psico-USF, 15(3), 345-356. https:// doi.org/10.1590/S1413-82712010000300008

Moreira-Almeida, A. (2007). Espiritualidade e saúde: passado e futuro de uma relação controversa e desafiadora [Editorial]. Revista de Psiquiatria Clínica, 34(1), 3-4. https://doi.org/10.1590/S0101-6083200700070 0001

Neme, C. M. B., Barbosa, C. G., Taboriansky, D., Figueiredo, P. C., Kakuda, R. M., Rebelo Júnior, S. L. ... Paiva, M. M. (2010). O contato com a morte de pacientes no serviço de oncologia hospitalar. In C. M. B. Neme (Org.), Psico-oncologia: caminhos e perspectivas (pp.237-281). São Paulo: Summus.

Ohnsorge, K., Gudat, H., \& Rehmann-Sutter, C. (2014). What a wish to die can mean: Reasons, meanings and functions of wishes to die, reported from 30 qualitative case studies of terminally ill cancer patients in palliative care. BioMed Central Palliative Care, 13(38), 1-14. https://doi.org/10.1186/1472-684X-13-38.
Olsson, L., Ostlund, G., Strang, P., Grassman, E. J., \& Friedrichsen, M. (2010). Maintaining hope when close to death: Insight from cancer patients in palliative home care. International Journal of Palliative Nursing, 16(12), 607-612. https://doi.org/10.12968/ijpn. 2010.16.12.607

Olver, I. N. (2012). Evolving definitions of hope in oncology. Current Opinion in Supportive and Palliative Care, 6(2), 236-241. https://doi.org/10.1097/SPC. Ob013e3283528d0c

Penha, R. M., \& Silva, M. J. P. (2012). Significado de espiritualidade para a enfermagem em cuidados intensivos. Texto e Contexto Enfermagem, 21(2), 260-268. https://doi.org/10.1590/S0104-07072012000200 002

Puchalski, C. M. (2012). Spirituality in cancer trajectory. Annals of Oncology, 23(3), 49-55. https://doi.org/ 10.1093/annonc/mds088

Puchalski, C. M. (2013). Integrating spirituality into patient care: An essential element of person-centered care. Polish Archives of Internal Medicine, 123(9), 491-497. Retrieved June 20, 2014 from http://pamw. pl/en/issue/article/24084250

Puchalski, C., Ferrel, B., Virani, R., Otis-Green, S., Baird, P., Bull, J. ... Sumasy, D. (2009). Improving the quality of spiritual care as a dimension of palliative care: The report of the consensus conference. Journal of Palliative Medicine, 12(10), 885-904. https://doi.org/ 10.1089/jpm.2009.0142

Saad, M., Masiero, D., \& Battistella, L. R. (2001). Espiritualidade baseada em evidências. Acta Fisiátrica, 8(3), 107-112. Recuperado em março 3, 2014, de http://www.amebrasil.org.br/html/espirit_evidencias. pdf

Saporetti, L. A. (2009). A espiritualidade em cuidados paliativos. In F. S. Santos (Org.), Cuidado paliativo: discutindo a vida, a morte e o morrer (pp.269-273). São Paulo: Atheneu.

Valle, J. E. R. (2005). Religião e espiritualidade: um olhar psicológico. In M. M. Amatuzzi (Org.), Psicologia e espiritualidade (pp.83-107). São Paulo: Paulus.

Recebido: fevereiro 10, 2015

Versão final: agosto 4, 2015

Aprovado: fevereiro 16, 2016 
